\title{
Fingerprint-based background checks for personal care workers: Stakeholder views of policy criteria
}

\author{
Authors: Eric D. Raile, Sarah J. Swierenga, Toni A. \\ Dennis, Lauren A. Swanson-Aprill, Lori A. Post, and \\ Fuad Abujarad
}

This is an Accepted Manuscript of an article published in Journal of Elder Abuse \& Neglect on May 2017, available online: http://www.tandfonline.com/10.1080/08946566.2017.1330715.

Raile, Eric D, Sarah J Swierenga, Toni A Dennis, Lauren A Swanson-Aprill, Lori A Post, and Fuad Abujarad. "Fingerprint-based background checks for personal care workers: Stakeholder views of policy criteria." Journal of Elder Abuse \& Neglect (May 2017): 1-18. DOI: 10.1080/08946566.2017.1330715.

Made available through Montana State University's $\underline{\text { ScholarWorks }}$ scholarworks.montana.edu 


\title{
Fingerprint-based Background Checks for Personal Care Workers: Stakeholder Views of Policy Criteria
}

\author{
Eric D. Raile, Ph.D. [Corresponding author] \\ Montana State University \\ eric.raile@montana.edu \\ Sarah J. Swierenga, Ph.D. \\ Michigan State University \\ sswieren@msu.edu \\ Toni A. Dennis \\ State of Michigan \\ DennisT@michigan.gov \\ Lauren A. Swanson-Aprill, M.A.
}

Michigan Department of Health \& Human Services, Aging and Adult Services Agency

SwansonL1@michigan.gov

Lori A. Post, Ph.D.

Northwestern University

lori.post@northwestern.edu

Fuad Abujarad, Ph.D.

Yale School of Medicine

fuad.abujarad@yale.edu

Acknowledgements: The authors would like to acknowledge the following individuals: Laura

Miller and Karla Fales of the Region 3B Area Agency on Aging (AAA); Jennifer Ismirle of Usability/Accessibility Research Consulting at Michigan State University; the Region 2 AAA, Region IV AAA, and Region 6 Tri-County Office on Aging; and home care providers and personal care workers who collaborated with or participated in the Michigan Workforce Background Check Enhancement - Pilot Program.

Funding: The Michigan Workforce Background Check Enhancement - Pilot Program was supported by Grant Number 1A1CMS33188-01-00 to the Michigan Department of Licensing and Regulatory Affairs (LARA) from the U.S. Department of Health and Human Services (DHHS), Centers for Medicare and Medicaid Services (CMS) National Background Check Demonstration Project, Catalog of Federal Domestic Assistance (CFDA) 93.506.

Disclaimer: The information or content and conclusions are those of the authors and should not be construed as the official position or policy of, nor should any official endorsement be inferred by, the State of Michigan-LARA, CMS, DHHS, or the U.S. Government. 


\begin{abstract}
Decision makers face difficult choices when tasked with identifying and implementing appropriate mechanisms for protecting the elderly and other vulnerable adults from abuse. A pilot project involving fingerprint-based criminal history background checks for personal care workers in Michigan has supplied an opportunity to examine one such mechanism. In conjunction with the pilot project, we have conducted a stakeholder analysis with the aim of informing decision makers about stakeholder perceptions of standard policy criteria like effectiveness, efficiency, and equity. We employed focus groups and a web-based survey to collect data from stakeholders. While stakeholders generally see fingerprint-based background checks for personal care workers as potentially effective and as a net benefit, they also point to a variety of contingencies. They also recognize difficulties and constraints for government involvement. This preliminary analysis provides solid foundational information for decision makers and for more extensive benefit-cost analysis.
\end{abstract}


FINGERPRINT-BASED BACKGROUND CHECKS

Identifying feasible and appropriate mechanisms for protecting the elderly and other vulnerable adults from abuse can be challenging. Abuse of such adults is an objectively important problem, whether the abuse takes the form of physical abuse, verbal abuse, theft, financial abuse, or neglect (see Harris, 1999; Page, Conner, Prokhorov, Fang, \& Post, 2009; Post, Page, Conner, Prokhorov, Fang, \& Biroscak, 2010; Rabiner, O’Keeffe, \& Brown, 2004; Zhang et al., 2011). Background checks or criminal history screenings for those persons potentially working with vulnerable adults are among the potential protection mechanisms (see Connolly, 2010; Radcliff, White, West, Hurd, \& Côté, 2013). The present study examines stakeholder perceptions of fingerprint-based criminal history background checks (hereafter "fingerprintbased background checks") for personal care workers (PCWs) as part of a pilot project in Michigan. $^{1}$

${ }^{1}$ Personal care aides/workers are part of a broader category of "direct care workers," which is a category that also includes nursing assistants or nursing aides and home health aides (Paraprofessional Healthcare Institute, 2011a). The literature uses the terms "long-term care worker" and "home care aide" synonymously with direct care worker. PCWs are persons who work with vulnerable adults outside of long-term care facilities. Later discussion of expanding background checks to PCWs potentially includes all persons with direct access to participants receiving supports and services outside of long-term care facilities. The term "vulnerable adult" is generic but is used synonymously here with "participants receiving supports and services," or persons receiving care or assistance from PCWs outside long-term care facilities. 
FINGERPRINT-BASED BACKGROUND CHECKS

The importance of economic concerns in this issue area drove the overall research approach for the study. Protection mechanisms must deal with fiscal constraints and the broader contexts of supply and demand. The number of Americans requiring long-term care is ballooning as baby boomers age (Friedland, 2004; National Center for Health Workforce Analyses, 2004; Paraprofessional Healthcare Institute, 2011a), and supplying care to meet this demand is already a significant challenge. The negative influences on labor supply for the long-term care workforce are relatively well known. The turnover rate due to low pay, work stress and overload, lack of social or relational support, and lack of upward mobility is a crucial part of the supply problem (Brannon, Barry, Kemper, Schreiner, \& Vasey, 2007; Bridges \& Turnham, 2013; Ejaz, Noelker, Menne, \& Bagaka's, 2008; Gray-Stanley \& Muramatsu, 2011; Kemper et al., 2008; National Center for Healthcare Workforce Analyses, 2004; Skirrow \& Hatton, 2007). The under-provision of healthcare insurance and the lack of compensation for driving costs also cause considerable recruitment and retention difficulties, particularly among PCWs (Bridges \& Turnham, 2013; Paraprofessional Healthcare Institute, 2007; 2011a; 2011b).

Given the nature of these concerns, we approach the issue using standard policy analysis criteria like effectiveness, efficiency, and equity (see Kraft \& Furlong, 2015). While this is an exploratory study rather than a causal analysis or complete policy analysis, the gathering of stakeholder perceptions can serve as an important preliminary stage of policy analysis by identifying important considerations. One might think of such work as "analysis for policy development" (Brugha \& Varvasovszky, 2000). Key stakeholders are a valuable source of information, as they are the people most acquainted with the likely benefits and costs of different courses of action. 
FINGERPRINT-BASED BACKGROUND CHECKS

This study will provide information relevant to various associated concerns. First, the employment of qualified (i.e., safe) PCWs potentially reduces broader social and economic costs. Second, some worry that stricter background check procedures for direct care workers (DCWs) in long-term care facilities have pushed criminals into the homes of vulnerable adults. Fingerprint-based background checks for PCWs could be a mechanism for alleviating this problem. Third, the U.S. government could mandate fingerprint-based background checks for PCWs in the future, and states would need to understand their options. Finally, the U.S. needs to make important decisions in the near future about the rising costs of long-term care. These decisions must address how private markets and governments contribute to solving these problems, respectively. This study explores such questions of private and public sector involvement.

\section{Background Information}

Though research on the use of checks and screenings to prevent elder abuse in particular is limited, the literature does offer a good deal of information more generally. Researchers have studied the use of background checks in pre-employment processes and have balanced giving those with criminal histories a chance at employment against the objective of ensuring a safe, high-quality workforce (Aamodt, 2015; Gerlach, 2006; Harris \& Keller, 2005; Rodriguez \& Emsellem, 2011; Smith, 2014; Valdez, 2015). Finding the right balance depends on the types of crimes previously committed and on redemption and recidivating by those with criminal histories, an area of considerable work (see Blumstein \& Nakamura, 2009; Bushway, Nieuwbeerta, \& Blokland, 2011; D’Alessio, Stolzenberg, \& Eitle, 2014; Kurlychek, Brame, \& Bushway, 2007; Zettler, Morris, Piquero, \& Cardwell, 2015). Importantly, the specific question of the actual effectiveness of criminal history background checks in preventing abuse of 
FINGERPRINT-BASED BACKGROUND CHECKS

vulnerable adults by DCWs remains an open one (Connolly, 2010; Galantowicz, Crisp, Karp, \& Accius, 2010; Radcliff et al., 2013).

More directly relevant to the present study, Radcliff et al. (2013) in this journal provide an evaluation of a pilot program for criminal history screening of long-term care workers in seven states. One of the major questions that emerges in their study concerns who should pay for the criminal history screenings, which include fingerprint-based background checks. Those authors look specifically at DCWs in formal long-term care settings, so the present study differs in its population of workers. The present study also delves more systematically into perceived benefits and costs and into the question of paying for criminal history screenings.

The U.S. government requires fingerprint-based background checks for limited sets of individuals in the direct care workforce through Medicare and Medicaid regulations (see Additional Screening Requirements, 2011; CMS, 2013). ${ }^{2}$ Studies have examined background check requirements and procedures across states for direct access employees (Borsky, Stewart, Carta, Gritz, \& McMahon, 2012), nurses (Alley, Marrs, \& Schreiner, 2005), nursing assistants (Lewin Group, 2006), nursing facilities (DHHS Office of Inspector General, 2011), caregiver agencies (Lindquist et al., 2012), and home care workers (Galantowicz et al., 2010). States generally exceed the national requirements for DCW background checks.

\footnotetext{
${ }^{2}$ These rules primarily cover individuals with ownership interests in care provider organizations deemed high risk (42 CFR $\S 424.518$ and 42 CFR $\S 455.434)$. Another set of rules (42 CFR $\S$ 418.114) requires criminal background checks for all hospice employees with direct patient contact or access to patient records.
} 
FINGERPRINT-BASED BACKGROUND CHECKS

Background check requirements for long-term care workers in the state of Michigan vary. Michigan mandates fingerprint-based background checks for individuals with direct access to residents at a range of licensed or certified facilities. The state pays for checks at adult foster care facilities and homes for the aged, while the provider pays otherwise. The state uses the Michigan Workforce Background Check (MWBC) system to check several name-based registries and to check fingerprints in Michigan and Federal Bureau of Investigation (FBI) criminal records. Potential employers receive a yes/no determination about an applicant. ${ }^{3}$ Michigan also requires name-based criminal history screenings, using the Internet Criminal History Access Tool (ICHAT), for entities associated with the Michigan Medicaid MI Choice Waiver program (MI Choice). The waiver agency and/or care provider agency is responsible for covering the costs. The Home Help Services program and waiver programs administered by the Behavioral Health and Developmental Disabilities Administration (BHDDA) do not currently require fingerprintbased background checks. ${ }^{4}$ However, many of these workers have already completed fingerprintbased background checks for other purposes. A name-based check of state criminal history records, including a check of state and federal databases, is completed on those PCWs applying to the Home Help Services or BHDDA waiver program. Additionally, ICHAT checks are required for all paid staff and volunteers that work directly with participants receiving supports

\footnotetext{
${ }^{3}$ The system includes a state "rapback" function that notifies employers immediately if an employee is later arrested, arraigned, or convicted (Abujarad, Swierenga, Dennis, \& Post, 2013). ${ }^{4}$ Approximately $90 \%$ of the more than 65,000 participants receiving supports and services via Home Help Services in Michigan are "self-determined" or "self-directed," meaning they do not hire PCWs through care provider agencies.
} 
FINGERPRINT-BASED BACKGROUND CHECKS

and services under programs funded by the Michigan Department of Health and Human Services, Aging and Adult Services Agency (AASA) or an Area Agency on Aging (AAA). In sum, Michigan currently has no formal, uniform statewide standard for conducting background checks on DCWs across programs.

The federal Centers for Medicare \& Medicaid Services (CMS) awarded funding to the Michigan Department of Licensing and Regulatory Affairs (LARA) to improve the existing background check system (see U.S. Department of Health and Human Services, 2013). The improvements included a pilot project that expanded the statewide, fingerprint-based background check system for long-term care facilities to some PCWs on a temporary, trial basis. Michigan made the MWBC available to certain care provider agencies voluntarily, with the costs of the pilot background checks (approximately $\$ 55$ per individual) being covered by the grant funds.

\section{Policy Analysis Criteria}

Structuring this research around the policy analysis criteria of effectiveness, efficiency, and equity served two basic purposes. First, these criteria shaped the types of questions posed to stakeholders via the focus group and survey instruments and the subsequent categorization and preliminary analysis of stakeholder perceptions. Second, use of these criteria allows stakeholder perceptions to serve as useful precursors to more formal benefit-cost analysis and as inputs to decision making.

This section elaborates on the meaning of these criteria and provides key definitions (see Kraft \& Furlong, 2015). Effectiveness is a question of whether a proposed course of action will "work" (i.e., achieve the set goals and objectives). Efficiency is an assessment of the relationship of benefits to costs. Equity deals with the distribution of benefits, costs, and risks across different 
FINGERPRINT-BASED BACKGROUND CHECKS

groups and is related to the concepts of fairness and justice. This final criterion of equity is an important one for the question of who might pay for fingerprint-based background checks.

The criterion of effectiveness hinges, in part, on an assessment of whether a proposed solution is likely to address the problem as understood. Analysis, then, benefits from examination of stakeholder understandings of the problem(s). Is the situation really a "problem?" Is the proposed solution likely to work directly on this particular problem? In the case of fingerprint-based background checks, the likely problem as understood by stakeholders is abuse of vulnerable adults, and the goal is therefore protection of vulnerable adults. Perceptions of effectiveness, then, will relate to how well stakeholders believe fingerprint-based background checks protect vulnerable adults.

In terms of efficiency, one type of market failure (i.e., inefficiency in private markets) seems most directly relevant for fingerprint-based background checks. "Information failure" is a form of market failure that results from insufficient information when making transactions. Typically, this means the person purchasing the good or service knows less about its quality than does the seller. This information asymmetry is a source of inefficiency that distorts transactions. PCWs know much more about their fitness and quality than do potential employers, and hiring poorly can have significant costs for the potential employer. Background checks can produce information to help reduce this asymmetry.

Returning to the criterion of equity, prices are the usual way for coordinating supply and demand in a free-market approach. In this case, vulnerable adults who could afford the additional costs of having a PCW that has undergone a fingerprint-based background check would get such a service, while their poorer counterparts would not. From a social welfare perspective, this type of price discrimination might not be acceptable, just, or fair for these particular services. In other 
FINGERPRINT-BASED BACKGROUND CHECKS

words, stakeholders might see the situation as unfair if individual inability to pay for fingerprintbased background checks potentially exposed vulnerable adults to abuse.

\section{Methods \& Data}

We chose a case study design to best meet the study objectives within the given resource constraints. The methods included focus groups and a web-based survey, followed by the use of qualitative data analysis software to categorize and examine the resulting qualitative data.

\section{Stakeholders}

Taken as a whole, this study is a stakeholder analysis (see Brugha \& Varvasovszky, 2000; Schmeer, 2000) that uses standard policy analysis criteria to organize stakeholder perceptions. An important early step of a stakeholder analysis is identification of key stakeholders. We aimed to collect views from a set of key stakeholder groups that would possess the most relevant information. In line with existing guidance (see Schmeer, 2000), our working group of researchers and government employees identified stakeholders through review of documents and discussion of experts' experiences. Narrowing the list to "priority stakeholders" involved identifying those stakeholders who were directly interested and had the ability to affect the proposed policy's implementation (Schmeer, 2000).

The identification of key stakeholders resulted in the following categories: (1) participants receiving supports and services (i.e., older adults and persons with disabilities), as well as their relatives and advocates; (2) PCWs and applicants for PCW positions; (3) employees of waiver agents and fiscal intermediaries; (4) owners/employees of care provider agencies; (5) employees of nongovernmental organizations (NGOs) whose work intersects with background checks and/or the healthcare workforce; and (6) government employees whose work intersects with background checks and/or the healthcare workforce. Waiver agents (category 3) can 
FINGERPRINT-BASED BACKGROUND CHECKS

determine whether an individual qualifies to receive supports and services at home or in a setting of her or his choosing. Fiscal intermediaries (category 3 ) help individuals with financial matters and/or help organizations with activities like payroll; they also may conduct background checks on behalf of organizations or on behalf of individuals hiring their own PCWs. Care provider agencies (category 4) are either firms or non-profit organizations that hire PCWs, who then go into the homes of participants receiving supports and services. Some of the NGOs (category 5) work from the perspective of participants receiving supports and services, while some others work from the PCW perspective. Government employees (category 6) were situated at the county and state levels.

\section{Focus Groups}

We organized five focus group sessions in south central Michigan to gather information and feedback from stakeholders (except for the government employee category) in a "multiple category" design (see Kruegar \& Casey, 2015). The Region 3B AAA, AASA (formerly the Michigan Office of Services to the Aging), and LARA assisted with identification and recruitment of focus group participants and with logistics for focus group sessions. ${ }^{5}$ The goal in sampling was to ensure representation of: participants receiving supports and services both through agencies and on their own; large and small care providers; for-profit and nonprofit care providers; PCWs working for agencies and independently; and a comprehensive set of NGOs.

\footnotetext{
${ }^{5}$ Focus group participants for the two non-professional groups (i.e., participants receiving supports and services and PCWs) received grocery store gift cards as an incentive for participation.
} 
FINGERPRINT-BASED BACKGROUND CHECKS

The contacting entities reached out to potential research participants by telephone, letter, and/or email.

In terms of additional technical details, the target size for each focus group was 6-10 participants, with each session lasting from 75-90 minutes. The actual number of focus group participants was: 12 in the participants receiving supports and services group, 13 in the PCWs group, 6 in the waiver agent and fiscal intermediary group, 7 in the care provider agencies group, and 6 in the NGO group. Two note takers and two digital audio recorders were present for each session. A professional subsequently transcribed the audio recordings and had access to the field notes. We used one of two sets of semi-structured questions in each focus group session depending on the nature of the group. Each question set included a series of questions about effectiveness (e.g., potential outcomes, potential social problems addressed, potential impact on security, satisfaction with the pilot project) and about efficiency (e.g., potential benefits and costs). We expected equity concerns (e.g., distribution of costs and benefits, ability to pay) to emerge as a consequence of the effectiveness and efficiency items. Other technical questions in the focus group instruments about effects on organizational processes are beyond the scope of the present study.

\section{Web-based Survey}

We also collected information via a web-based survey distributed to employees of both governmental and nongovernmental organizations. The survey included both open- and closedended items. We used a survey based on a few considerations. First, the focus group format was not optimal for collecting information from all stakeholder groups. In particular, government employees might offer a great deal of detailed technical information and would be difficult to schedule all at once. Second, a scheduling conflict during the week of the focus groups meant 
FINGERPRINT-BASED BACKGROUND CHECKS

that some personnel from invited NGOs were not available. Third, the survey allowed us to follow up on certain topics that emerged in the focus groups and to explore some topics in greater depth, though the survey language largely mirrored the focus group instruments. Fourth, the survey allowed for a check on whether the focus groups had achieved saturation of relevant topics and ideas.

We recruited 30 individuals via email to participate in the survey. Pilot project leads from MWBC, LARA, and AASA supplied contact information for the mix of government and NGO employees. The contacted individuals represented essentially the entire population of relevant persons, even including a few who decided they did not know enough to comment. The time between the initial recruitment email and the survey closing was 18 days. After following up on multiple occasions, the response rate for the survey was $60 \%$ (i.e., 18 responses), which represents a solid majority of the entire population.

\section{Coding}

Coding of the focus group transcripts and the open-ended survey responses proceeded using a deductive coding approach (see Miles, Huberman, \& Saldaña, 2014), after delinking responses from identifying information. We used software (NVivo10) to organize the data into nodes derived from the three policy analysis criteria of effectiveness, efficiency, and equity. The pre-existence of these nodes was the core of the deductive coding approach. This organization would permit analysis of perceived potential performance against these criteria. The closedended survey items produced frequency distributions and marginal percentages.

\section{Data Organization \& Analysis}

This section organizes the data resulting from the focus groups and from the survey based on the policy analysis criteria of effectiveness, efficiency, and equity. This organization process 
FINGERPRINT-BASED BACKGROUND CHECKS

allows for analysis of how a requirement for fingerprint-based background checks for PCWs prospectively holds up against these criteria according to stakeholders. Unless otherwise indicated, the primary goal was comprehensive identification of the variety of viewpoints related to each criterion.

\section{Effectiveness Criterion}

The analysis of effectiveness begins with evaluation of stakeholder understanding of problems in this issue area. Stakeholders across all the focus groups and the survey believe that insufficiencies exist with regard to the current system for ensuring a qualified PCW workforce. PCWs and participants receiving supports and services see current government funding as insufficient to cover needs in this area. Survey respondents (government and NGO employees) agree with the assertion that the following are insufficiencies in the current system: lack of uniform, statewide standards (83.3\% agreed); lack of data or information from national lists and databases (55.6\%); insufficient protection of participants receiving supports and services (55.6\%); and the lack of fingerprint-based background checks (50.0\%). Across the focus groups, stakeholders also indicate the types of potential PCW behaviors that society needs to prevent. A comprehensive list of such behaviors includes: financial exploitation and fraud (e.g., getting written into a vulnerable adult's will); physical and sexual abuse; mental and emotional abuse; theft; drug use and prescription drug theft; dishonesty; and aggressive behavior.

[Table 1 about here]

Table 1 presents additional information related to the criterion of effectiveness. Generally speaking, the data discussed in the previous paragraph and the data shown in Table 1 point toward a conclusion that stakeholders see fingerprint-based background checks as a reasonable solution. Survey respondents largely see fingerprint-based background checks for PCWs as being 
FINGERPRINT-BASED BACKGROUND CHECKS

at least somewhat effective in addressing a variety of abuse and related problems. Stakeholders in at least two of the focus groups (PCWs and providers) believe such checks improve the actual and/or perceived safety of vulnerable adults. However, stakeholders also believe the effectiveness of fingerprint-based background checks will be contingent on a variety of factors. Table 1 contains a comprehensive list of such contingencies. Importantly, stakeholders worry about fingerprint-based background checks being an actual or perceived unfunded mandate, which could hamper effectiveness. Licensing and certification also appear here. Certification of PCWs would most likely involve completion of approved training programs or educational curricula. Many stakeholders view certification as useful, though covering costs is a problem. The State of Michigan is examining its options with regard to certification.

\section{Efficiency Criterion}

Table 2 presents data relevant to the criterion of efficiency, starting with the perceived prospective benefits of instituting a requirement for PCWs to undergo fingerprint-based background checks. Stakeholders generally think such a requirement could represent an improvement. The comments listed in Table 2 emphasize specific prospective improvements as compared to the current system. This comprehensive listing of improvements starts with the prospects for improved workforce quality. Stakeholders (participants receiving supports and services, PCWs, care provider agencies, waiver agents, and survey respondents) broadly believe such background checks could legitimize and professionalize the industry. Such background checks are required in related healthcare professions. The data also point toward potential technical improvements and reductions in errors. Comments about cost savings relate primarily to potential reductions in PCW turnover and reduced liability for care provider agencies.

[Table 2 about here] 
FINGERPRINT-BASED BACKGROUND CHECKS

Table 2 also summarizes potential costs as projected by stakeholders. The supply of PCWs is a serious concern, especially given anticipated growth in demand. However, some ambivalence is evident here. Some stakeholders believe that job applicants being excluded by the system should not be in the workforce regardless of the problem of labor supply. Other stakeholders think the state would need to phase in such a system and/or would need to grandfather in current workers to avoid an abrupt workforce disruption. Survey responses are more uniform in their concern, citing problems with existing workforce shortages and the downswing in PCW supply during times of economic improvement. Stakeholders also worry about deterring good employees. They observe that potential PCWs have other employment options that do not require fingerprint-based background checks. Beyond the workforce concerns, the survey responses also reveal concern about increased costs and PCW privacy.

Finally, Table 2 provides information about direct comparison between benefits and costs. Though only $11 \%$ of survey respondents believe the costs of requiring fingerprint-based background checks for PCWs outweigh the benefits, a third of respondents are not sure. That leaves a slight majority of respondents who think the prospective benefits are greater than the prospective drawbacks. The comments also include some proposed tests for balancing benefits against costs.

\section{Equity Criterion}

Table 3 presents information related to the criterion of equity (i.e., distribution of benefits and costs), starting with payment and price issues. Overall, stakeholders clearly understand the complications resulting from the low pay of PCWs, the poverty of many vulnerable adults, and government funding limitations. The respective stakeholder groups have differing ideas about who should be paying, with ideas including the state, health insurance companies, PCWs, care 
FINGERPRINT-BASED BACKGROUND CHECKS

provider agencies, and participants receiving supports and services. Some stakeholders suggest spreading the costs out over multiple entities. The focus groups with care provider agencies, PCWs, and participants receiving supports and services all believe their own group could not bear the costs. The PCWs suspect care provider agencies can afford the costs, but the care provider agencies assert their margins are too thin. Various focus groups argue that PCWs or participants receiving supports and services ultimately would end up paying the costs, regardless of the initial payment mechanism. Importantly, some NGOs point out that state law prohibits job applicants from paying for fingerprinting. NGOs also suggest the system would collapse if the state did not pay for fingerprint-based background checks for cases of direct hire of PCWs. Finally, survey respondents show a fair degree of concern over the issue of who would pay for the fingerprint-based background checks for PCWs.

[Table 3 about here]

Table 3 also lists stakeholder feedback that deals with information failure as a particular form of market failure that can affect equity. To reiterate, a majority of survey respondents identify the lack of information from national lists and databases as an insufficiency in the system. Stakeholders also point to errors with name-based systems. Beyond a relatively high false positive rate, current name-based systems collect potentially irrelevant information, use different names for the same offenses, and aggregate or count felonies in different ways. Stakeholders also widely believe that a requirement for fingerprint-based background checks would serve as a serious deterrent for unqualified PCWs, thus simplifying the informational environment and hiring processes. Both PCWs and care provider agencies prominently and repeatedly point to the importance of these deterrence effects, citing similar experiences with the effects of drug testing. Table 3 also lists stakeholder views of the consequences of such 
FINGERPRINT-BASED BACKGROUND CHECKS

information failure, which relate primarily to confusion and to felons ending up in the homes of participants receiving supports and services.

Finally, the potential response of stakeholders to a requirement for fingerprint-based background checks for PCWs is an important equity consideration. How will stakeholder groups react to the distribution of costs and benefits? As shown in Table 3, survey respondents believe the response of participants receiving supports and services would be considerably more positive than the response from PCWs.

\section{Recommendations}

This final section provides recommendations based on the process of gathering information from stakeholders and based on the organization and analysis of their views. First, given the importance of protecting the elderly and other vulnerable adults, evaluations of programs designed to protect them from abuse should involve a range of stakeholders in the information-gathering process. In our study, stakeholders have different views about costs, benefits, and their distribution. These varied views should all be part of a well-informed dialogue, given that an inequitable distribution of costs and benefits could be a real hardship with far-ranging consequences for vulnerable populations. We believe our approach has resulted in a comprehensive and well-informed initial look at the issue.

Second, governments should think in holistic ways about the quality of DCWs in general and of PCWs more specifically. Stakeholders emphasize that preventing abuse of vulnerable adults depends on implementing an integrated system for PCW quality. Using a holistic approach and getting the surrounding rules right are notions that fit well with other studies of the issue area (see, for example, DHHS Office of Inspector General, 2011; Galantowicz et al., 2010; Lewin Group, 2006). Fortunately, governments interested in making improvements need not start from 
FINGERPRINT-BASED BACKGROUND CHECKS

scratch. Research produced mostly by government agencies and NGOs has provided ideas about ways to fill existing gaps. These studies have addressed training (Lewin Group, 2006; Luz, Swanson, Ochylski, \& Turnham, 2014; Paraprofessional Healthcare Institute, 2011b); appeals, rehabilitation, and waivers (Borsky et al., 2012; Galantowicz et al., 2010; Lewin Group, 2006); and better mechanisms for processing misconduct (Borsky et al., 2012).

Third, authorities making decisions in this issue area should recognize the importance of contingencies, as pointed out by stakeholders. Such contingencies are especially apparent in thinking about potential effectiveness and efficiency and in thinking about implementation challenges. The answers here are not necessarily straightforward or simple.

Fourth, the question of who pays for services for vulnerable adults (often with fixed incomes) is a crucial one that governments should work to resolve directly and clearly. Partial funding of a program can create inequities in service access and shortfalls in service supply. Answering this type of payment question is not easy, and states come to different answers about who pays. Fingerprint-based background checks cost money in an industry short on cash from all sides. If authorities cannot resolve the cost issue, stakeholders think fingerprint-based background checks should be available to participants receiving supports and services, PCWs, and/or care provider agencies on a voluntary basis.

Fifth, communities should think carefully about the role of government even beyond the payment issue. Stakeholders suggest different forms of government involvement. The labor market economics in this industry (in particular demand for PCWs outstripping supply) and problems of information failure support an argument for significant government involvement. This issue area also invokes privacy and data concerns - domains that often lead to government involvement. Further, while privatizing certain elements of the process (e.g., fingerprinting itself) 
FINGERPRINT-BASED BACKGROUND CHECKS

is possible, the federal government already mandates intervention by state governments in this issue area overall.

Sixth, researchers and governments should explore opportunities for further analysis in this issue area, particularly given its broader applicability to demand for long-term care. The question of how much actual security these background checks provide when applied to this particular workforce remains unanswered. Further, while this study has laid groundwork by identifying many of the relevant factors in detail, a fully monetized benefit-cost analysis could prove useful. Estimations of effects on labor supply also seem worthwhile, though at least one study has found no negative impact of background checks on the applicant pool size at nursing facilities (Lewin Group, 2006). More extensive research could clearly reveal the longer-term benefits and costs for governments in ways that make decision making easier. Replication of this research in other locations could also be instructive. Subsequent research might more carefully consider the broader social benefits and costs related to these types of background checks, as well. The social costs of inaction might include violating social values tied to protection of vulnerable adults, broader worrying about safety, and the increased burden for the criminal justice system and other entities dealing with the aftermath of abuse. 
FINGERPRINT-BASED BACKGROUND CHECKS

\section{References}

Aamodt, M. G. (2015). Using background checks in the employee selection process. In C. Harvey \& K. Sady (Eds.), Practitioner's guide to legal issues in organizations (pp. 85110). New York: Springer.

Abujarad, F., Swierenga, S. J., Dennis, T. A., \& Post, L. A. (2013). Rap backs: Continuous workforce monitoring to improve patient safety in long-term care. In A. Marcus (Ed.), Design, user experience, and usability: User experience in novel technological environments (pp. 3-9). New York: Springer.

Additional Screening Requirements, 76 Fed. Reg. 22 (February 2, 2011) (to be codified at 42 C.F.R. pts. $405,424,455,457,498, \& 1007)$.

Alley, N. M., Marrs, J., \& Schreiner, B. (2005). Nurses' promise to safeguard the public. JONA's Healthcare Laws, Ethics, and Regulation, 7(4), 119-124.

Blumstein, A., \& Nakamura, K. (2009). Redemption in the presence of widespread criminal history background checks. Criminology, 47(2), 327-359. doi:10.1111/j.17459125.2009.00155.x

Borsky, A., Stewart, J., Carta C., Gritz, M., \& McMahon, J. (2012). Report: Centers for Medicare \& Medicare Services, National Background Check Program, Long Term Care Criminal Convictions Work Group. Retrieved from http://www.cms.gov/Medicare/Provider-Enrollment-andCertification/SurveyCertificationGenInfo/Downloads/Survey-and-Cert-Letter-13-24Attachment-.pdf 
FINGERPRINT-BASED BACKGROUND CHECKS

Brannon, D., Barry, T., Kemper, P., Schreiner, A., \& Vasey, J. (2007). Job perceptions and intent to leave among direct care workers: Evidence from the Better Jobs Better Care demonstrations. The Gerontologist, 47(6), 820-829.

Bridges, T., \& Turnham, H. (2013). Findings from Medicaid home and community-based provider organizations surveys: Understanding Michigan's long-term supports and services workforce. Retrieved from http://phinational.org/sites/phinational.org/files/surveys-focus-groups/provider-surveysxsum.pdf

Brugha, R., \& Varvasovszky, Z. (2000). Stakeholder analysis: A Review. Health Policy and Planning, 15(3), 239-246. doi:10.1093/heapol/15.3.239

Bushway, S. D., Nieuwbeerta, P., \& Blokland, A. (2011). The predictive value of criminal history background checks: Do age and criminal history affect time to redemption? Criminology, 49(1), 27-60. doi:10.1111/j.1745-9125.2010.00217.x

CMS. (2013). Implementation of fingerprint-based background checks. (MLN Matters Number SE1417.) Retrieved from http://www.cms.gov/Outreach-and-Education/MedicareLearning-Network-MLN/MLNMattersArticles/Downloads/SE1417.pdf

Connolly, M. T. (2010). Where elder abuse and the justice system collide: Police power, parens patriae, and 12 recommendations. Journal of Elder Abuse \& Neglect, 22, 37-93.

D’Alessio, S. J., Stolzenberg, L., \& Eitle, D. (2014). 'Last hired, first fired': The effect of the unemployment rate on the probability of repeat offending. American Journal of Criminal Justice, 39, 77-93. doi:10.1007/s12103-013-9199-1

DHHS Office of Inspector General. (2011). Nursing facilities' employment of individuals with criminal convictions. Retrieved from https://oig.hhs.gov/oei/reports/oei-07-09-00110.pdf 
FINGERPRINT-BASED BACKGROUND CHECKS

Ejaz, F. K., Noelker, L. S., Menne, H. L., \& Bagaka’s, J. G. (2008). The impact of stress and support on direct care workers' job satisfaction. The Gerontologist, 48(Special Issue I), 60-70. doi:10.1093/geront/48.Supplement_1.60

Friedland, R. B. (2004). Caregivers and long-term care needs in the 21st century: Will public policy meet the challenge? Retrieved from http://caregiverslibrary.org/Portals/0/caregivers\%20and\%20LTC\%20needs\%20and\%20P ublic\%20Policy.pdf

Galantowicz, S., Crisp, S., Karp, N., \& Accius J. (2010). Safe at home? Developing effective criminal history background checks and other screening policies for home care workers. Retrieved from AARP Public Policy Institute website: http://assets.aarp.org/rgcenter/ppi/ltc/2009-12.pdf

Gerlach, E. A. (2006). The background check balancing act: Protecting applicants with criminal convictions while encouraging criminal history background checks in hiring. University of Pennsylvania Journal of Labor \& Employment Law, 8, 981-1000.

Gray-Stanley, J. A., \& Muramatsu, N. (2011). Work stress, burnout, and social and personal resources among direct care workers. Research in Developmental Disabilities, 32, 10651074. doi:10.1016/j.ridd.2011.01.025

Harris, D. (1999). Elder abuse in nursing homes: The theft of patients' possessions. Journal of Elder Abuse \& Neglect, 10(3/4), 141-151. doi:10.1300/J084v10n03_08

Harris, P. M., \& Keller, K. S. (2005). Ex-offenders need not apply: The criminal history background check in hiring decisions. Journal of Contemporary Criminal Justice, 21(1), 6-30. doi:10.1177/1043986204271678 
FINGERPRINT-BASED BACKGROUND CHECKS

Kemper, P., Heier, B., Barry, T., Brannon, D., Angelilli, J., Vasey, J., \& Anderson-Knott, M. (2008). What do direct care workers say would improve their jobs? Differences across settings. The Gerontologist, 48(Special Issue I), 17-25. doi:10.1093/geront/48.Supplement_1.17

Kraft, M. E., \& Furlong, S. R. (2015). Public policy: Politics, analysis, alternatives (5th ed.). Washington, D.C.: CQ Press.

Kruegar, R. A.., \& Casey, M. A. (2015). Focus groups: A practical guide for applied research (5th ed.). Thousand Oaks, CA: Sage Publications, Inc.

Kurlychek, M. C., Brame, R., \& Bushway, S. D. (2007). Enduring risk? Old criminal records and predictions of future criminal involvement. Crime \& Delinquency, 53(1), 64-83. doi:10.1177/0011128706294439

Lewin Group. (2006). Ensuring a qualified long-term care workforce: From pre-employment screens to on-the-job monitoring. Retrieved from http://aspe.hhs.gov/daltcp/reports/2006/LTCWqual.pdf

Lindquist, L. A., Cameron, K. A., Messerges-Bernstein, J., Friesma, E., Zickuhr, L. Baker, D. W., \& Wolf, M. (2012). Hiring and screening practices of agencies supplying paid caregivers to older adults. Journal of the American Geriatrics Society, 60(7), 1253-1259. doi:10.1111/j.1532-5415.2012.04047.x

Luz, C., Swanson, L., Ochylski, D., \& Turnham, H. (2014). Michigan's 'Building Training ... Building Quality' personal and home care aide state training program. Final report for the Michigan Office of Services to the Aging. Retrieved from http://phinational.org/sites/phinational.org/files/research-report/michphcast-finalreport20141219.pdf 


\section{FINGERPRINT-BASED BACKGROUND CHECKS}

Miles, M. B., Huberman, A. M., \& Saldaña, J. (2014). Qualitative data analysis: A methods sourcebook (3rd ed.). Los Angeles: Sage.

National Center for Health Workforce Analyses. (2004). Nursing aides, home health aides, and related health care occupations - National and local workforce shortages and associated data needs. Retrieved from http://bhpr.hrsa.gov/healthworkforce/reports/rnhomeaides.pdf

Page, C., Conner, T., Prokhorov, A., Fang, Y., \& Post, L. (2009). The effect of care setting on elder abuse: Results from a Michigan survey. Journal of Elder Abuse \& Neglect, 21, 239252. doi:10.1080/08946560902997553

Paraprofessional Healthcare Institute. (2007). When Michigan's caregivers lack coverage: Findings from a survey of Michigan's Home Help workforce. Report to the Michigan Quality Home Care Coalition. Retrieved from http://phinational.org/sites/phinational.org/files/research-report/hchcw_misurvey.pdf

Paraprofessional Healthcare Institute (2011a). Facts 3: Who are direct-care workers? Retrieved from http://www.phinational.org/sites/phinational.org/files/clearinghouse/NCDCW\%20Fact\% 20Sheet-1.pdf

Paraprofessional Healthcare Institute (2011b). Self-determination and MI Choice Medicaid Waiver Program: A survey of direct-care workers serving people using the MI Choice self-determination option. Retrieved from http://phinational.org/sites/phinational.org/files/surveys-focus-groups/phimichsdworkersurvey-oct2011.pdf 
FINGERPRINT-BASED BACKGROUND CHECKS

Post, L., Page, C., Conner, T., Prokhorov, A., Fang, Y., \& Biroscak, B. J. (2010). Elder abuse in long-term care: Types, patterns, and risk factors. Research on Aging, 32(3), 323-348. doi:10.1177/0164027509357705

Rabiner, D. J., O’Keeffe, J., \& Brown, D. (2004). A conceptual framework of financial exploitation of older persons. Journal of Elder Abuse \& Neglect, 16(2), 53-73. doi:10.1300/J084v16n02_05

Radcliff, T. A., White, A., West, D. R., Hurd, D., \& Côté, M. J. (2013). Evaluation of a seven state criminal history screening pilot program for long-term care workers. Journal of Elder Abuse \& Neglect, 25(5), 375-395. doi:10.1080/08946566.2013.780955

Rodriguez, M. N., \& Emsellem, M. (2011). 65 million need not apply: The case for reforming criminal history background checks for employment. Retrieved from: http://nelp.org/content/uploads/2015/03/65_Million_Need_Not_Apply.pdf

Schmeer, K. (2000). Section 2: Stakeholder analysis guidelines. Retrieved from: http://www.who.int/workforcealliance/knowledge/toolkit/33.pdf?ua=1

Skirrow, P., \& Hatton, C. (2007). 'Burnout' amongst direct care workers in services for adults with intellectual disabilities: A systematic review of research findings and normative data. Journal of Applied Research in Intellectual Disabilities, 20, 131-144.

Smith, J. J. (2014). Banning the box but keeping the discrimination? Disparate impact and employers' overreliance on criminal background checks. Harvard Civil Rights-Civil Liberties Law Review, 49, 197-228.

U.S. Department of Health and Human Services. (2013). Nationwide program for national and state background checks for direct patient access employees of long term care facilities and providers. (Ninth Announcement CFDA \#93.506.) Retrieved 


\section{FINGERPRINT-BASED BACKGROUND CHECKS}

from https://www.cms.gov/Medicare/Provider-Enrollment-andCertification/SurveyCertificationGenInfo/downloads/nbgcpgmsoli.pdf

Valdez, C. (2015). Hands-tied hiring: How the EEOC's individualized assessment is taking discretion away from employers' use of criminal background checks. Cleveland State Law Review, 63, 541-566.

Zettler, H. R., Morris, R. G., Piquero, A. R., \& Cardwell, S. M. (2015). Assessing the celerity of arrest on 3-year recidivism patterns in a sample of criminal defendants. Journal of Criminal Justice, 43(5), 428-436. doi:10.1016/j.jcrimjus.2015.05.003

Zhang, Z., Schiamberg, L. B., Oehmke, J., Barboza, G. E., Griffore, R. J., Post, L. A., Weatheril, R. P., \& Mastin. T. (2011). Neglect of older adults in Michigan nursing homes. Journal of Elder Abuse \& Neglect, 23, 58-74. doi:10.1080/08946566.2011.534708 
Table 1

Views on prospective effectiveness of fingerprint-based background checks for PCWs

Summary of open-ended comments from focus groups and surveys

- Such checks improve perceived and actual security/safety of vulnerable adults, providing peace of mind (PCWs, providers)

- Prospective effectiveness depends on a range of other factors, including:

$\circ$ Establishing adequate systems for evaluating and training PCWs

- Implementing appropriate appeal, rehabilitation, and waiver mechanisms

- Establishing appropriate incentives for the investigation and prosecution of wrongdoing

- Having appropriate funding for administration and enforcement

- Choosing the correct policies and implementation strategies

- Resolving the issue of who pays for background checks

- Being able to link checks to procedures for licensing providers and for certifying PCWs

- Being able to integrate with systems like ICHAT, motor vehicle records, and drug testing

- Appropriately covering all relevant individuals in the entire state, including owners of care provider agencies and PCWs hired without federal funds or in self-determination situations

- Adequately supporting participants receiving supports and services in the case of worker ineligibility or refusal of the participant to sign a waiver

How effective do you think expansion of the fingerprint-based background check requirement to personal care workers would be in addressing ...

Physical abuse

\begin{tabular}{rcrrr} 
Very & Somewhat & Not very & Not at all & Unsure \\
\hline $0.0 \%$ & $83.3 \%$ & $11.1 \%$ & $0.0 \%$ & $5.6 \%$ \\
$0.0 \%$ & $44.4 \%$ & $38.9 \%$ & $11.1 \%$ & $5.6 \%$ \\
$5.6 \%$ & $83.3 \%$ & $5.6 \%$ & $0.0 \%$ & $5.6 \%$ \\
$33.3 \%$ & $50.0 \%$ & $0.0 \%$ & $5.6 \%$ & $11.1 \%$
\end{tabular}

How concerned are you about the following ...

Government authority

\begin{tabular}{ccccc} 
Very & Somewhat & Not very & Not at all & Unsure \\
\hline $29.4 \%$ & $29.4 \%$ & $23.5 \%$ & $0.0 \%$ & $17.6 \%$ \\
$47.1 \%$ & $41.2 \%$ & $5.9 \%$ & $0.0 \%$ & $5.9 \%$
\end{tabular}

Note. A parenthetical following a comment indicates the groups in which such a comment arose prominently. Otherwise, comments are aggregated comprehensively across all data sources. The other reported results are from closed-ended survey items, the population for which was NGO and government employees working in related fields. The total number of survey respondents was 17 or 18 , depending on the item. The government authority and capacity items relate to enforcing a requirement of fingerprint-based background checks for PCWs. In some cases, we may have slightly altered the question or response wording from the survey to accommodate table space constraints. Marginal percentages may not total $100.0 \%$ exactly due to rounding. 
FINGERPRINT-BASED BACKGROUND CHECKS

Table 2

Views on prospective efficiency of fingerprint-based background checks for PCWs

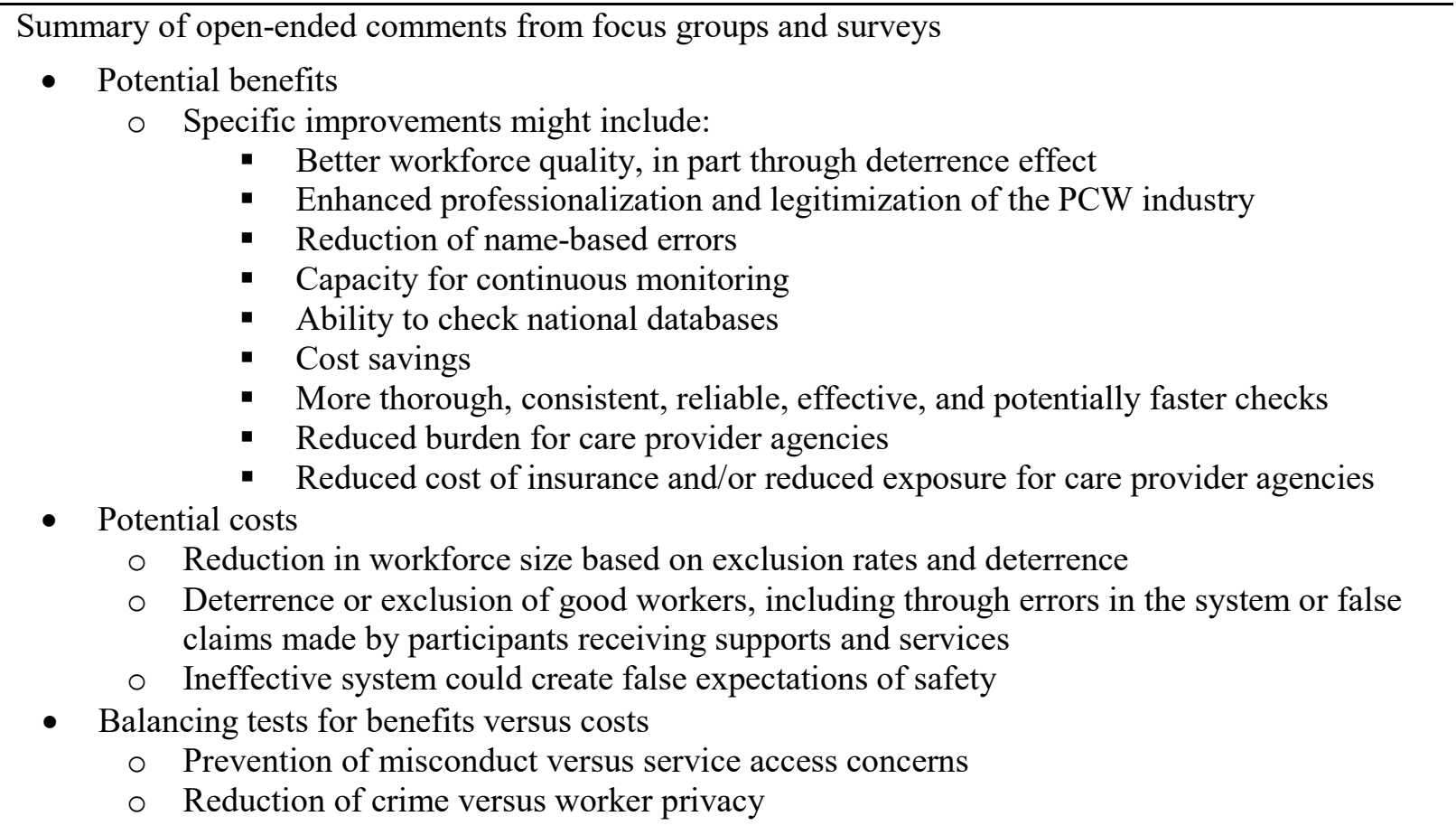

\begin{tabular}{|c|c|c|c|c|c|}
\hline \multicolumn{6}{|c|}{ How concerned are you about the following ... } \\
\hline & Very & Somewhat & Not very & Not at all & Unsure \\
\hline Increased costs & $33.3 \%$ & $44.4 \%$ & $16.7 \%$ & $5.6 \%$ & $0.0 \%$ \\
\hline Privacy of workers & $16.7 \%$ & $33.3 \%$ & $33.3 \%$ & $16.7 \%$ & $0.0 \%$ \\
\hline Decreased workforce & $27.8 \%$ & $33.3 \%$ & $22.2 \%$ & $11.1 \%$ & $5.6 \%$ \\
\hline \multirow{2}{*}{\multicolumn{3}{|c|}{ Are benefits of such checks greater than drawbacks? }} & Yes & No & Unsure \\
\hline & & & $56.0 \%$ & $11.0 \%$ & $33.0 \%$ \\
\hline
\end{tabular}

Note. Comments are aggregated comprehensively across all data sources. The other reported results are from closed-ended survey items, the population for which was NGO and government employees working in related fields. The total number of survey respondents was 17 or 18, depending on the item. In some cases, we may have slightly altered the question or response wording from the survey in order to accommodate table space constraints. Marginal percentages may not total $100.0 \%$ exactly due to rounding. 
Table 3

Views on prospective equity of fingerprint-based background checks for PCWs

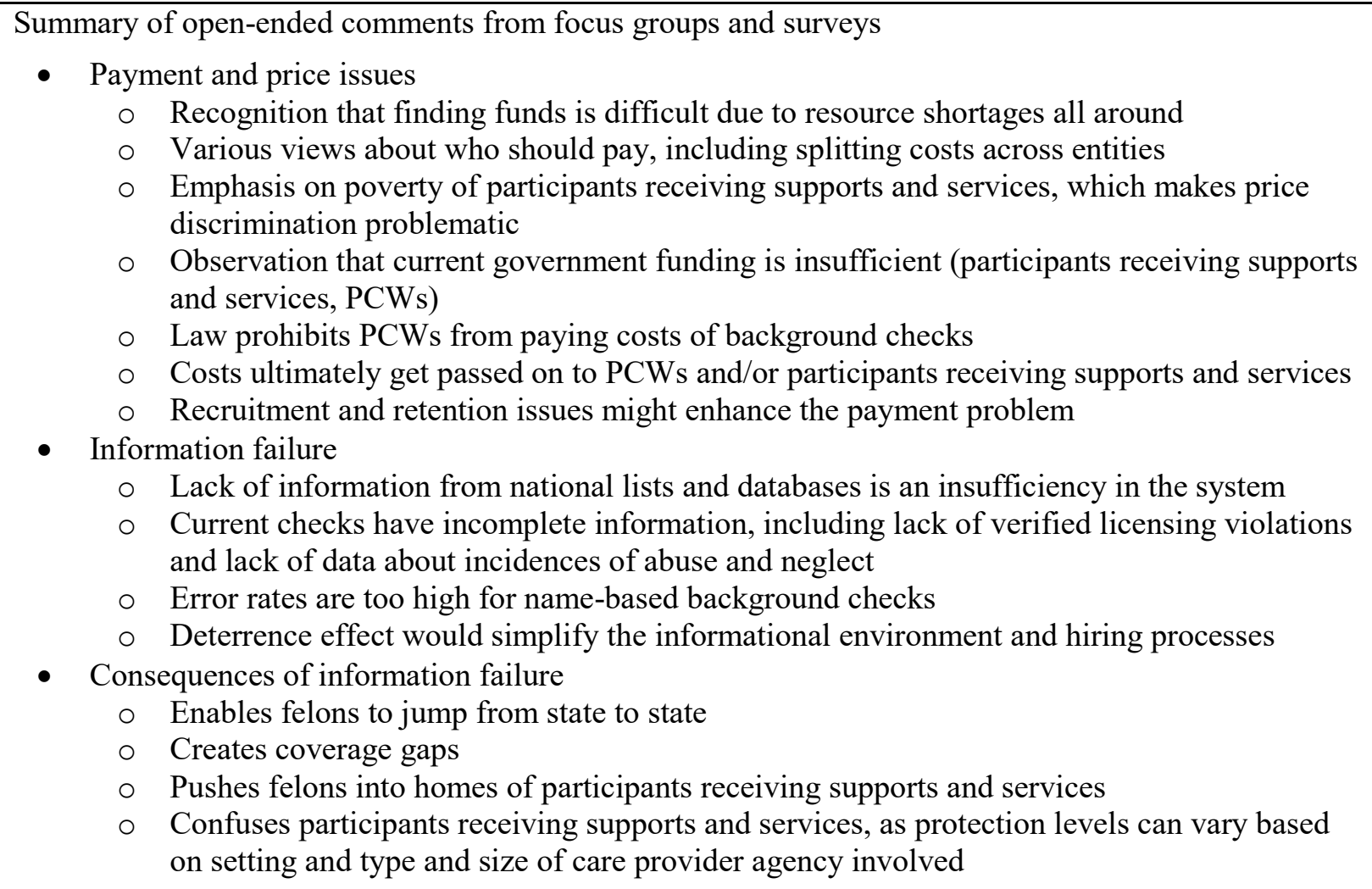

\begin{tabular}{|c|c|c|c|c|c|c|}
\hline \multicolumn{7}{|c|}{ How concerned are you about the following ... } \\
\hline \multirow[b]{2}{*}{ Who pays for checks } & \multirow{2}{*}{$\begin{array}{c}\text { Very } \\
44.4 \%\end{array}$} & Somewhat & \multicolumn{2}{|c|}{ Not very } & Not at all & \multirow{2}{*}{$\begin{array}{c}\text { Unsure } \\
0.0 \%\end{array}$} \\
\hline & & $33.3 \%$ & 22 & & $0.0 \%$ & \\
\hline \multicolumn{7}{|c|}{ Projected response to fingerprint-based background check requirement on the part of ... } \\
\hline & $\begin{array}{c}\text { Very } \\
\text { favorable }\end{array}$ & $\begin{array}{c}\text { Fairly } \\
\text { favorable }\end{array}$ & $\begin{array}{c}\text { Not too } \\
\text { favorable }\end{array}$ & $\begin{array}{l}\text { Not at all } \\
\text { favorable }\end{array}$ & Depends & Unsure \\
\hline Participants & $38.9 \%$ & $22.2 \%$ & $5.6 \%$ & $5.6 \%$ & $22.2 \%$ & $5.6 \%$ \\
\hline PCWs & $0.0 \%$ & $44.4 \%$ & $27.8 \%$ & $16.7 \%$ & $11.1 \%$ & $0.0 \%$ \\
\hline
\end{tabular}

Note. A parenthetical following a comment indicates the groups in which such a comment arose prominently. Otherwise, comments are aggregated comprehensively across all data sources. The other reported results are from closed-ended survey items, the population for which was NGO and government employees working in related fields. The total number of survey respondents was 17 or 18 , depending on the item. In some cases, we may have slightly altered the question or response wording from the survey in order to accommodate table space constraints. Marginal percentages may not total $100.0 \%$ exactly due to rounding. 